\title{
Nano-investigation on Grain Boundary Periodic Alternating Segregation Based on Divorced Coincident Segregation Mechanism, Resulted in the Replacement of Conventional Site Competition in Steels
}

\author{
Hidesato MABUCHI and Toshihiko KOSEKI"1) \\ Formerly Oita R\&D Laboratories, Nippon Steel Corporation. Now at Department of R\&D, The Japan Research and \\ Development Center for Metals, Toranomon, Minato-ku, Tokyo 105-0001 Japan. \\ 1) Oita R\&D Laboratories, Nippon \\ Steel Corporation, Nishinosu, Oita, Oita-ken 870-8566 Japan.
}

(Received on February 15, 2000; accepted in final form on April 24, 2000)

\begin{abstract}
The segregation mechanism of alloying elements in prior austenitic grain boundaries of embrittled $5 \% \mathrm{Ni}$ steels has been investigated by AES in previous studies, while that of improved $5 \%$ Ni steels has not been clarified yet. In the present study, the segregating behavior of alloying elements in improved $5 \% \mathrm{Ni}$ steels has been elucidated for the first time by applying FE-TEM with respect to the effects of soluble Al on the suppression of temper embrittlement and hydrogen embrittlement in the steels.

It is consequently made clear by applying FE-TEM-EDS that alloying elements tend to segregate coincidently to grain boundaries, showing the asymmetric segregation according to solute interactions. The observed behavior is newly defined as the divorced coincident segregation, which is considered to result from the moderate site competitions in the deep potential well of McLean's equilibrium segregation. The divorced coincident segregation was investigated further along grain boundaries, where the periodic segregation of $\mathrm{Al}$ and Si was found to vary alternately along grain boundaries analyzed.

The beneficial effect of soluble Al on the two types embrittlement is attributed to the mechanism of spot toughening through the periodic decrease of solutes in grain boundaries. The principle of the divorced coincident segregation proposed in $5 \% \mathrm{Ni}$ steels can be applicable not only to ordinary steels but also to other poly-crystalline alloys in improving their properties.
\end{abstract}

KEY WORDS: segregation mechanism; cosegregation; site competition; divorced coincident segregation; asymmetric segregation; periodic alternating segregation; alloying element; aluminum; solute interaction; repulsive interaction; temper embrittlement; hydrogen embrittlement; spot toughening; $5 \%$ nickel steel; plaincarbon steel; HY130 steel; AES; FE-TEM; FE-TEM-EDS.

\section{Introduction}

It is well revealed by previous studies that the brittle fracture of steels is induced by the grain boundary segregation of solutes. ${ }^{1-11)}$ Alloying elements and impurities tend to segregate to grain boundaries during heat treatments or high temperature services, while hydrogen also segregates to the regions of high lattice expansion due to an applied tension stress.

Many investigators reported the influence of grain boundary segregation of $\mathrm{Mn}, \mathrm{Si}$ and impurities on the temper embrittlement of $\mathrm{Cr}-\mathrm{Mo}$ steels, ${ }^{1,2)} \mathrm{Ni}-\mathrm{Cr}$ steels ${ }^{3,4)}$ and a $5 \% \mathrm{Ni}$ steel (HY130). ${ }^{5}$ ) On the other hand, the threshold stress intensity were shown to be lowered drastically in a $\mathrm{Ni}-\mathrm{Cr}$ steel $^{6)}$ and a $5 \% \mathrm{Ni}$ steel $^{7)}$ in the aqueous solution of $\mathrm{H}_{2} \mathrm{SO}_{4}$, when the steels were aged so as to produce temper embrittlement.

Later, the $5 \%$ Ni steel was tested in hydrogen gas instead of the aqueous solution to avoid uncertainties of electro- chemical conditions, and the result showed synergy between the temper embrittlement and the hydrogen embrittlement. ${ }^{8)}$ In order to clarify further this interaction between hydrogen and segregated alloying elements, $5 \% \mathrm{Ni}$ steels with systematic changes in composition were studied with respect to the effects of soluble $\mathrm{Al}$ on the two types of embrittlement. $^{9-11)}$ It was first found that an addition of $0.30 \%$ $\mathrm{Al}$ and a removal of $\mathrm{Si}$ and $\mathrm{Mn}$ from $5 \% \mathrm{Ni}$ steels were beneficial to attain almost complete resistance to the two types of embrittlement. ${ }^{9,10)}$

However, the above-mentioned investigations on the segregation mechanism of solutes in grain boundaries were commonly carried out by conducting Auger Electron Spectroscopy (AES) analyses on the fractured surfaces, ${ }^{1-11)}$ assuming the symmetric segregation of solutes. ${ }^{12)}$ It was then impossible to clarify the segregating behavior in the improved $5 \% \mathrm{Ni}$ steels by AES analyses, due to the absence of their intergranular fracture. ${ }^{7-11)}$

In the present study, the segregating behavior of alloying 
Table 1. Chemical composition of $5 \% \mathrm{Ni}$ steels and a plaincarbon steel.

\begin{tabular}{llllllllllll}
\hline Steel & $\mathrm{C}$ & $\mathrm{Si}$ & $\mathrm{Mn}$ & $\mathrm{P}$ & $\mathrm{S}$ & $\mathrm{Ni}$ & $\mathrm{Cr}$ & $\mathrm{Mo}$ & $\mathrm{V}$ & $\mathrm{Al}$ & $\mathrm{N}$ \\
\hline $\mathrm{A}$ & 0.14 & 0.01 & 0.02 & 0.001 & 0.001 & 4.90 & 0.51 & 0.50 & 0.075 & 0.300 & 0.002 \\
B & 0.14 & 0.02 & 0.92 & 0.002 & 0.001 & 4.90 & 0.51 & 0.50 & 0.074 & 0.320 & 0.003 \\
$\mathrm{C}$ & 0.14 & 0.32 & 0.92 & 0.002 & 0.002 & 4.90 & 0.51 & 0.50 & 0.076 & 0.299 & 0.004 \\
$\mathrm{D}$ & 0.11 & 0.34 & 0.88 & 0.003 & 0.005 & 4.88 & 0.57 & 0.49 & 0.080 & 0.020 & 0.010 \\
E & 0.13 & 0.31 & 0.90 & 0.003 & 0.004 & 4.97 & 0.48 & 0.50 & 0.079 & 0.025 & 0.002 \\
\hline X & 0.31 & 0.53 & 0.01 & 0.107 & 0.001 & - & - & - & - & 0.350 & 0.001 \\
\hline
\end{tabular}

elements in grain boundaries was investigated for the first time by adopting Field-Emission Transmission Electron Microscopy (FE-TEM) ${ }^{13,14)}$ equipped with Energy Dispersive X-Ray Spectroscopy (EDS) to the improved 5\% Ni steels without intergranular fractures. ${ }^{9,10)}$ "Divorced coincident segregation" with asymmetric profiles of segregated solutes has been newly defined for the segregation mechanism of alloying elements according to the moderate site competition in the deep potential well of McLean's equilibrium segregation. ${ }^{15}$ )

The divorced coincident segregation in the improved $5 \%$ $\mathrm{Ni}$ steels was further investigated by employing FE-TEMEDS to find the periodic alternating segregation along grain boundaries. ${ }^{16)}$ The three-dimensional contour map of segregated solutes was eventually proposed from adopting the point symmetric concept of the periodic alternating segregation based on the divorced coincident segregation mechanism.

Then, the present paper describes the formation mechanism of the periodic alternating segregation based on the divorced coincident segregation mechanism in the $5 \% \mathrm{Ni}$ steels and a plain-carbon steel, clearly demonstrating the repulsive interaction between $\mathrm{Al}$ and $\mathrm{Si}$ in grain boundaries.

\section{Experimental Procedures}

\subsection{Materials}

The composition of $5 \% \mathrm{Ni}$ steels provided in the present study is listed in Table 1. Steel D as the standard grade of HY130 is the production heat of a conventional $5 \% \mathrm{Ni}$ steel with $100 \mathrm{ppm} \mathrm{N}$ and $30 \mathrm{ppm} \mathrm{Sn}$, which are the general outcome from a refining process by using an electric furnace, while others are all laboratory heats with 20 to 40 ppm N and low impurities. Al content of Steels A, B and C was increased up to $0.3 \%$, but that of Steels D and E was kept around $0.025 \%$. Steels C, D and E have essentially the same composition except for $\mathrm{Al}$ and $\mathrm{N}$ contents. On the other hand, Si was removed from Steel B as the improved $5 \% \mathrm{Ni}$ steel, and both $\mathrm{Si}$ and $\mathrm{Mn}$ were removed from Steel $\mathrm{A}$ as the further improved steel. Besides, Steel $\mathrm{X}$ is provided as the additional laboratory heat of a plain-carbon steel with doped $\mathrm{P}$ of $0.1 \%$, to confirm the grain boundary periodic alternating segregation of $\mathrm{Al}$ and $\mathrm{Si}$ even in the absence of Ni, Cr, Mo and Mn.

Each steel was heat treated as following. ${ }^{10)}$ First, samples were austenitized at $1273 \mathrm{~K}$ for $7.2 \times 10^{3} \mathrm{~s}$, to obtain the same prior austenitic grain size as ASTM No. 5. Then, they were quenched and tempered at $898 \mathrm{~K}$ for $7.2 \times 10^{3} \mathrm{~s}$, to control the hardness to $R_{\mathrm{c}}=34.5 \pm 1.4$. Finally, they were isothermally aged at $753 \mathrm{~K}$ for times up to $3.6 \times 10^{6} \mathrm{~s}$, so as to determine the susceptibility to temper embrittlement and to hydrogen embrittlement.

\subsection{Mechanical Testing}

Charpy V-notch (CVN) impact test was carried out for the specimens of $5 \% \mathrm{Ni}$ steels both in the as-quenched and tempered condition and in the aged condition. The toughness of the steels was characterized by $50 \%$ Ductile-Brittle Fracture Appearance Transition Temperature (FATT). The resistance of the steels to temper embrittlement was then expressed by the shift of FATT, $\triangle$ FATT, before and after the ageing.

The susceptibility of the steels to hydrogen embrittlement after the ageing was measured by pre-cracked boltloaded, modified 1T-WOL specimens in hydrogen gas at $296 \pm 0.5 \mathrm{~K}$ with the pressure of $110.3 \pm 1.7 \times 10^{-3} \mathrm{MPa}$. The testing method of the modified WOL in hydrogen gas was described elsewhere in detail. ${ }^{10)}$ The resistance of the steels to hydrogen embrittlement was then expressed by the threshold stress intensity, $K_{\mathrm{Th}}$ after the ageing.

\subsection{FE-TEM Analyses}

The grain boundary segregation of alloying elements was analyzed by using FE-TEM, as described in the previous study. ${ }^{13)}$ The thin foil specimen with a thickness of $5 \mathrm{~nm}$ or less was mounted to the FE-TEM, and grain boundaries were observed by TEM mode and then analyzed by EDS mode with $1 \mathrm{~nm}$-probe. The analyses were carried out avoiding the neighborhood of existing precipitates. ${ }^{15)}$ The cross-sectional EDS analyses toward grain boundaries were performed in Steels B and C to investigate the concentration profiles of segregated solutes.

The EDS analyses along grain boundaries were also carried out for the distance of $10 \mathrm{~nm}$ in Steels $\mathrm{B}, \mathrm{C}$ and $\mathrm{D}$, to investigate the influence of $\mathrm{Al}, \mathrm{Si}$ and $\mathrm{Mn}$ on the grain boundary periodic alternating segregation based on the divorced coincident segregation mechanism. The EDS analyses along grain boundaries were additionally conducted for Steel $\mathrm{X}$ to confirm the grain boundary periodic alternating segregation of $\mathrm{Al}$ and $\mathrm{Si}$ even in the absence of $\mathrm{Ni}, \mathrm{Cr}, \mathrm{Mo}$ and $\mathrm{Mn}$.

\subsection{Simulations of Periodic Alternating Segregation}

Solute interaction in grain boundaries was estimated by using Thermo Calc, ${ }^{17)}$ to understand the periodic alternating segregation. ${ }^{16)}$ Grain boundaries are assumed to have the same structure as liquid phase or amorphous phase, and to have constant total Gibbs energy throughout, regardless of compositional variation within them.

The total Gibbs energy was determined by choosing one compositional set of the actual step-scan measurements. Then, the concentration profile of one solute was computed, assuming that the measured concentration data of the other solute were valid in the ternary system of interest. SSOL data base in Thermo Calc version L was employed in the present calculation. ${ }^{17)}$

In addition, the subsequent simulation was performed to investigate the effect of the third solute, which could com- 
pensate the change in the total Gibbs energy caused by the apparent cosegregation of $\mathrm{Al}$ and $\mathrm{Mn}$ in Steel B, as discussed later.

\section{Experimental Results}

\subsection{Mechanical Properties in $5 \%$ Ni Steels}

Table 2 shows the summary of temper embrittlement and hydrogen embrittlement associated with the cumulated compositional actions in $5 \% \mathrm{Ni}$ steels, as described elsewhere in detail. ${ }^{10)}$

Steel D as a production heat is quite susceptible both to temper embrittlement and to hydrogen embrittlement. The two types of embrittlement are decreased significantly by the reduction of $\mathrm{N}$. A further improvement is brought about by the addition of $\mathrm{Al}$, and still further by the removal of $\mathrm{Si}$ and $\mathrm{Mn}$.

The above result suggests a possibility to suppress hydrogen embrittlement by improving resistance to temper embrittlement or low-temperature toughness even without elucidating the segregation mechanism of alloying elements. ${ }^{9,10,15)}$

\subsection{EDS Analyses in Prior Austenitic Grain Bound- aries}

Figure 1 shows the influence of alloying elements in matrices of $5 \% \mathrm{Ni}$ steels on solute segregation in prior

Table 2. The summary of temper embrittlement and hydrogen embrittlement with the cumulated compositional actions in $5 \%$ Ni steels.

\begin{tabular}{llcc}
\hline Steel & Cumulated actions & $\begin{array}{c}\Delta \text { FATT } \\
(\mathrm{K})\end{array}$ & $\begin{array}{c}\mathrm{K}_{\mathrm{Th}} \\
\left(\mathrm{MN} \cdot \mathrm{m}^{-3 / 2}\right)\end{array}$ \\
\hline D & Standard HY130 (5\% Ni) & 250 & 22 \\
E & D + Decrease in N & 137 & 40 \\
C & E + Increase in Al & 63 & 51 \\
B & C + Removal of Si & 50 & 60 \\
A & B + Removal of Mn & 5 & 110 \\
\hline
\end{tabular}

austenitic grain boundaries after the ageing. In the present study, elements other than those shown in Fig. 1 were not detected, since their concentrations were less than the analyzing limit of 0.1 mass $\%$. However, only $\mathrm{P}$ was detected with the ranges of 0.2 to 0.3 mass $\%$ in Steel D. The results are summarized as follows. ${ }^{15)}$

Al Segregation: The matrix concentration of Al in Steel $\mathrm{C}$ enhances the grain boundary segregation of $\mathrm{Al}$ compared with Steels D and E. The removal of Mn from Steel A extremely increases the grain boundary segregation of $\mathrm{Al}$, presumably due to the lack of the site competition between $\mathrm{Al}$ and $\mathrm{Mn}$ in grain boundaries.

Si segregation: The grain boundary segregation of $\mathrm{Si}$ is significantly increased by the high matrix concentration of $\mathrm{Al}$ in Steel C with Si.

Cr Segregation: The segregating behavior of $\mathrm{Cr}$ seems to be adverse to that of $\mathrm{Si}$. The grain boundary segregation of $\mathrm{Cr}$ is enormously increased by higher matrix concentration of $\mathrm{N}$ in Steel D.

Mn Segregation: The segregating behavior of $\mathrm{Mn}$ is quite adverse to that of $\mathrm{Si}$. The grain boundary segregation of $\mathrm{Mn}$ is suppressed by the increased matrix concentration of $\mathrm{Al}$ in Steel $\mathrm{C}$ presumably due to the site competition between $\mathrm{Al}$ and $\mathrm{Mn}$ in grain boundaries, while that is remarkably enhanced by the removal of Si from Steel B even with high Al presumably due to the lack of the site competition between $\mathrm{Si}$ and $\mathrm{Mn}$ in grain boundaries.

However, it is difficult in Fig. 1 to distinguish the influence of matrix solute interaction from that of grain boundary one on the resultant solute segregation in grain boundaries.

\subsection{Cross-Sectional EDS Analyses toward Grain Boundaries}

Figure 2 plots the cross-sectional profiles of segregated alloying elements in Steel $\mathrm{C}$ with high $\mathrm{Al}$ with the distance from a grain boundary at $0 \mathrm{~nm} .{ }^{10}$ ) The concentration value at $0 \mathrm{~nm}$ for each solute shown in Fig. 2 corresponds to one of those plotted in Fig. 1. Al, Si and Mn have steep peaks in their segregation profiles right at the grain boundaries.

Asymmetric segregation is clearly observed in Fig. 2. Al tends to segregate to one side of a grain boundary, while $\mathrm{Si}$,
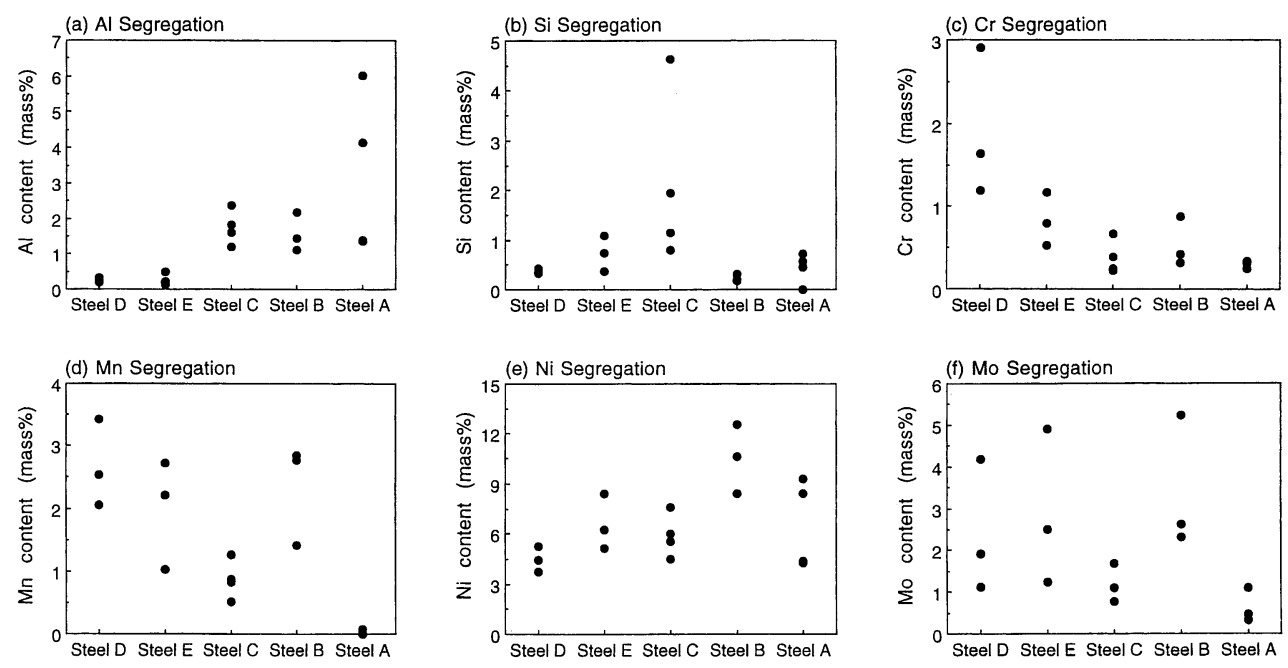

Fig. 1. The influence of alloying elements in matrices of $5 \% \mathrm{Ni}$ steels on other solute segregation in prior austenitic grain boundaries by EDS analyses. 

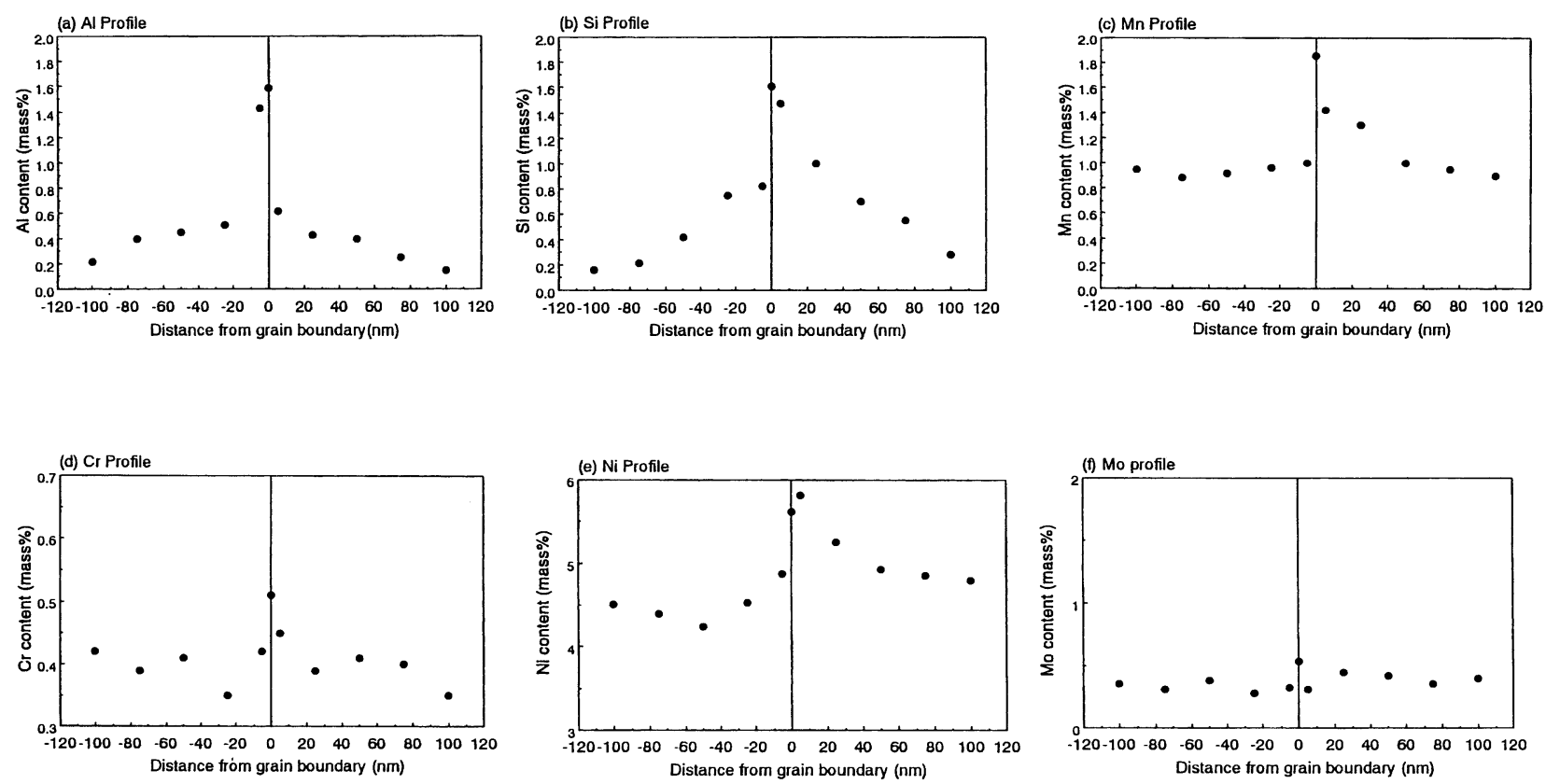

Fig. 2. The cross-sectional profiles of segregated alloying elements toward grain boundaries in 5\% Ni Steel C by EDS analyses.
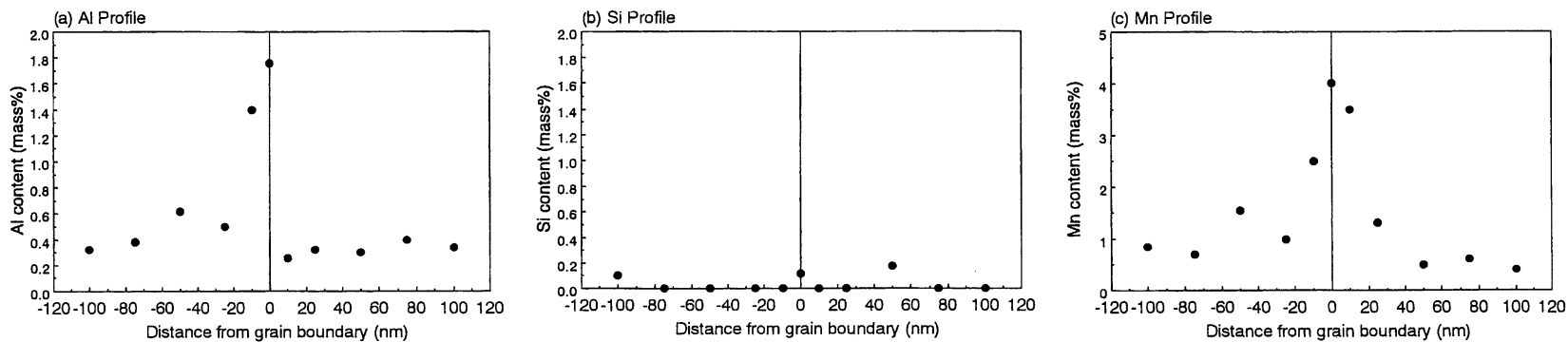

Fig. 3. The cross-sectional profiles of segregated alloying elements toward grain boundaries in $5 \% \mathrm{Ni}$ Steel B by EDS analyses.

$\mathrm{Mn}$ and $\mathrm{Ni}$ tend to segregate to the other side of the grain boundary.

Figure 3 also plots the cross-sectional profiles of segregated alloying elements in Steel B with high Al and low Si with the distance from a grain boundary. Al tends to segregate to one side of a grain boundary, while Mn tends to segregate to the other side of the grain boundary, which definitely shows asymmetric manner.

The above phenomena with the asymmetric segregation shown in Figs. 2 and 3 should lead to the divorced coincident segregation from a viewpoint of moderate site competitions in the deep potential well of McLean's equilibrium segregation, ${ }^{18)}$ as schematically depicted in Fig. 4. $^{15)}$ It is compared with conventional site competition and conventional cosegregation, supposing the symmetric profile of segregated solutes. ${ }^{12)}$

By the way, the conventional site competition in grain boundaries is commonly explained us the quantitative mutual displacement between solutes when the intergranular concentration of solute A decreases and that of solute B increases with the increased bulk concentration of solute B or with ageing time, since averaged values of segregated solutes are obtained in AES analyses in fractured surfaces. ${ }^{12,13,18)}$ Then, the one-dimensional model of the conventional site competition is taken into consideration to develop the three-dimensional model of solute segregation by adopting EDS analyses in the present nano investigation.

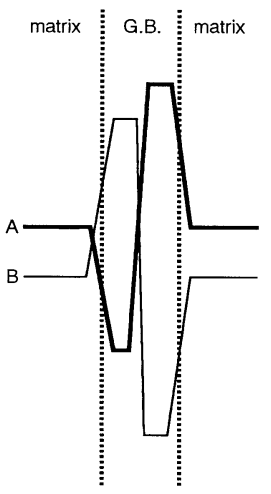

(a) Divorced coincident segregation

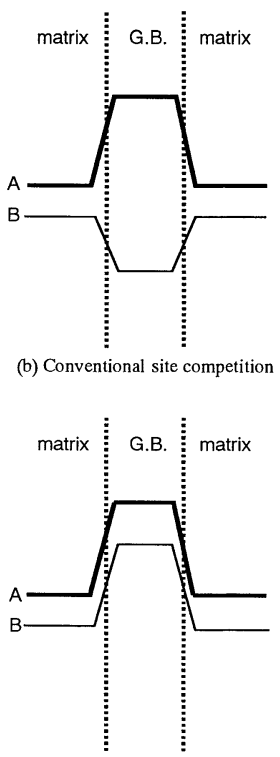

(c) Conventional cosegregation
Fig. 4. Schematic illustration of divorced coincident segregation compared with conventional site competition and conventional cosegregation.

The divorced coincident segregation will be composed of the following three basic processes. First, all the solutes including impurities tend to segregate to grain boundaries ac- 

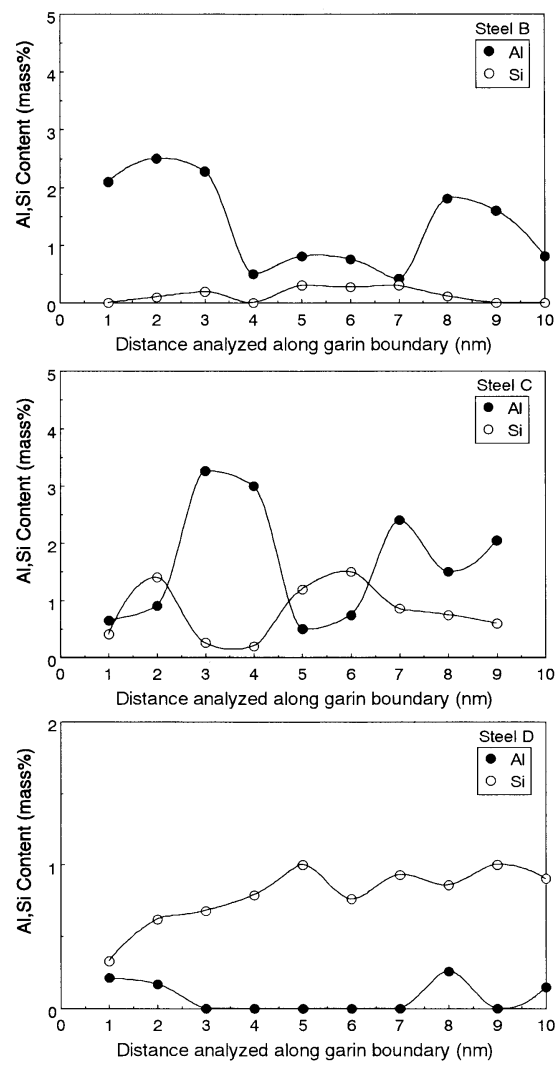

Fig. 5. The segregated concentrations of $\mathrm{Al}$ and $\mathrm{Si}$ with distance along grain boundaries in $5 \% \mathrm{Ni}$ Steels B, C and D by EDS analyses.

cording to the mechanism of McLean's equilibrium segregation. Second, alloying elements, which have attractive interactions each other, tend to cosegregate to one side of grain boundaries. Third, alloying elements, which have repulsive interactions each other, tend to occupy the opposite side of grain boundaries according to the moderate site competition, which may be caused by weaker driving force than that of McLean's equilibrium segregation.

The newly defined divorced coincident segregation can not be distinguished from the conventional site competition by AES analyses through one side observations of intergranularly fractured surfaces. It is also interesting to note that most of conventional site competition may have a great possibility to be replaced by the divorced coincident segregation by FE-TEM analyses. Hence, the conventional site competitions can be predicted to take place only in the case that the site competition is caused by stronger driving force than that of McLean's equilibrium segregation.

\subsection{EDS Analyses along Grain Boundaries}

Figure 5 shows the segregated concentrations of $\mathrm{Al}$ and $\mathrm{Si}$ analyzed by EDS along grain boundaries in Steels B, C and D. Interesting phenomena are observed in Fig. 5 regarding the repulsive interaction between $\mathrm{Al}$ and $\mathrm{Si}$.

Steel C shows obviously the periodic segregation of Al and $\mathrm{Si}$, which vary alternately by the cycle of about $3 \mathrm{~nm}$. In Steel $\mathrm{B}$ with low $\mathrm{Si}, \mathrm{Al}$ also varies periodically along the grain boundary, but Si does not change significantly. On the other hand in Steel D with low Al, the spot increase in $\mathrm{Al}$ is quite correspondent to the local decrease in $\mathrm{Si}$, although the periodic segregation of $\mathrm{Al}$ is not seen at all in Steel $\mathrm{D}$.
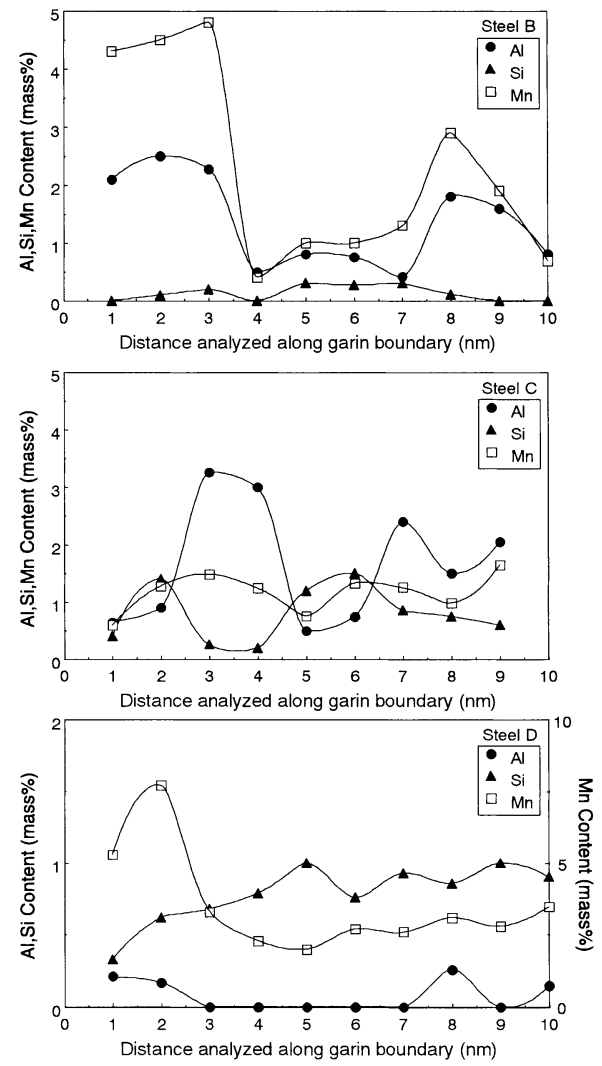

Fig. 6. The segregated concentrations of $\mathrm{Al}, \mathrm{Si}$ and $\mathrm{Mn}$ with distance along grain boundaries in 5\% Ni Steels B, C and D by EDS analyses.

The influence of the segregated concentration of $\mathrm{Al}$ and $\mathrm{Si}$ on that of Mn is shown in Fig. 6. It is noted in Steel B with low $\mathrm{Si}$ that the concentration of $\mathrm{Mn}$ is obviously related to that of Al, while that of Si does not seem to be related either to that of $\mathrm{Al}$ or $\mathrm{Mn}$. This observation implies that the presence of the third solute in Steel B may compensate the change in the total Gibbs energy caused by the apparent cosegregation of $\mathrm{Al}$ and $\mathrm{Mn}$. However, it is shown in Steel $\mathrm{C}$ that the concentration of $\mathrm{Mn}$ is not seen to be related at all either to that of $\mathrm{Al}$ or Si. On the other hand, it is observed in Steel D with low Al that the concentration of Mn is inversely related to that of $\mathrm{Si}$, if the local decrease in $\mathrm{Si}$ or the local increase in $\mathrm{Mn}$ is modified to be smooth by cancelling the influence of the spot increase in Al. Then, the periodic segregation of $\mathrm{Si}$ and $\mathrm{Mn}$ is considered to be the cycle of $8 \mathrm{~nm}$ in this case.

The above observations in Figs. 5 and 6 summarize that repulsive interactions are seen strongly between $\mathrm{Al}$ and $\mathrm{Si}$ and slightly between $\mathrm{Si}$ and $\mathrm{Mn}$, and that an attractive interaction is seen apparently between $\mathrm{Al}$ and $\mathrm{Mn}$ under the condition of low Si.

It is interesting to point out that the cycles of $3 \mathrm{~nm}$ on the periodic alternating segregation of $\mathrm{Al}$ and $\mathrm{Si}$ shown in Steel $\mathrm{C}$ is well correspondent to the wavelength of 1 to $3 \mathrm{~nm}$ on the spinodal decomposition in vapor deposited structures with positive interaction coefficient. ${ }^{19)}$ It is also noted that the cycles of $8 \mathrm{~nm}$ on the periodic alternating segregation of $\mathrm{Si}$ and $\mathrm{Mn}$ shown in Steel D is also correspondent to the wavelength of $10 \mathrm{~nm}$ on the spinodal decomposition in binary alloys with positive interaction coefficient. ${ }^{20)}$ 


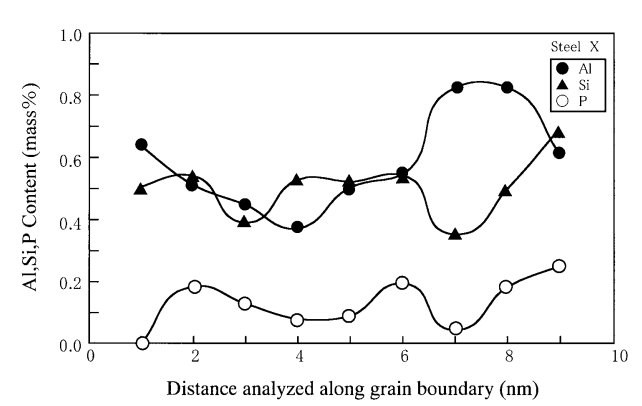

Fig. 7. The segregated concentrations of Al, Si and P with distance along a grain boundary in plain-carbon Steel $\mathrm{X}$ by EDS analyses.

\subsection{Further Investigation on Periodic Alternating Segregation in a Plain-carbon Steel}

The grain boundary periodic alternating segregation of $\mathrm{Al}$ and $\mathrm{Si}$ is now under investigation in simple systems. For instance, the plain-carbon steel of Steel X with doped P of $0.1 \%$ was provided to confirm the presence of the periodic alternating segregation even in the absence of $\mathrm{Ni}, \mathrm{Cr}, \mathrm{Mo}$ and $\mathrm{Mn}$. Figure 7 demonstrates the segregated concentrations of $\mathrm{Al}, \mathrm{Si}$ and $\mathrm{P}$ analyzed by EDS along a grain boundary in Steel X. The periodic segregation of $\mathrm{Al}$ and $\mathrm{Si}$ is clearly seen to vary alternately by the cycle of about $3 \mathrm{~nm}$, which is quite obvious at the distance from $6 \mathrm{~nm}$ to $10 \mathrm{~nm}$. The concentration of $\mathrm{P}$ does not seem to be related to that of $\mathrm{Al}$, although that of $\mathrm{P}$ is inversely related to that of $\mathrm{Al}$ partially at the distance from $6 \mathrm{~nm}$ to $10 \mathrm{~nm}$ without any controversy. ${ }^{10,21)}$

On the other hand, it is noted that the concentration of $\mathrm{Si}$ is clearly related to that of $\mathrm{P}$, although the attractive interaction between $\mathrm{Si}$ and $\mathrm{P}$ is not coincident with the previous data on interaction coefficient. ${ }^{10,21,22)}$ Hence, the cosegregation of $\mathrm{Si}$ and $\mathrm{P}$ is considered to be apparent presumably due to the presence of the third solute which has the strong repulsive interaction with $\mathrm{P}$.

The above observation in Fig. 7 elucidates that the periodic alternating segregation of $\mathrm{Al}$ and $\mathrm{Si}$ can take place even without any additions of $\mathrm{Ni}, \mathrm{Cr}$, Mo and $\mathrm{Mn}$. It is then concluded that the periodic alternating segregation of $\mathrm{Al}$ and $\mathrm{Si}$ is not a peculiar phenomenon in $5 \% \mathrm{Ni}$ steels but a common one in any kind of steels.

\section{Discussions}

\subsection{Influence of Solute Interactions on Grain Bound- ary Segregation in 5\% Ni Steels}

4.1.1. Resultant Solute Interactions Both in Matrices and Grain Boundaries of 5\% Ni Steels

Figures 8 and 9 show the correlation of grain boundary segregation between the selected alloying elements of interest. They were rearranged from averaged intergranular concentrations of alloying elements in the five $5 \% \mathrm{Ni}$ steels shown in Fig. 1. Two types of the segregating behavior of alloying elements are clearly observed in Figs. 8 and 9. Figure 8 shows an inversely proportional type of grain boundary segregation, while Fig. 9 shows a directly proportional type of that.

It is noted in Fig. 8 that repulsive interactions, which may cause divorced coincident segregation or site competition,
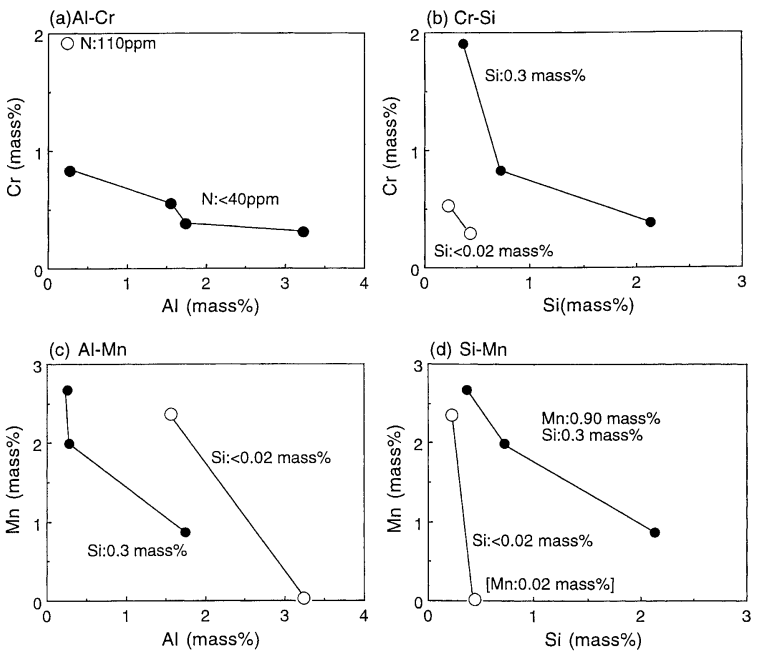

Fig. 8. The correlation of grain boundary segregation between selected two alloying elements in $5 \% \mathrm{Ni}$ steels as an inversely proportional type.
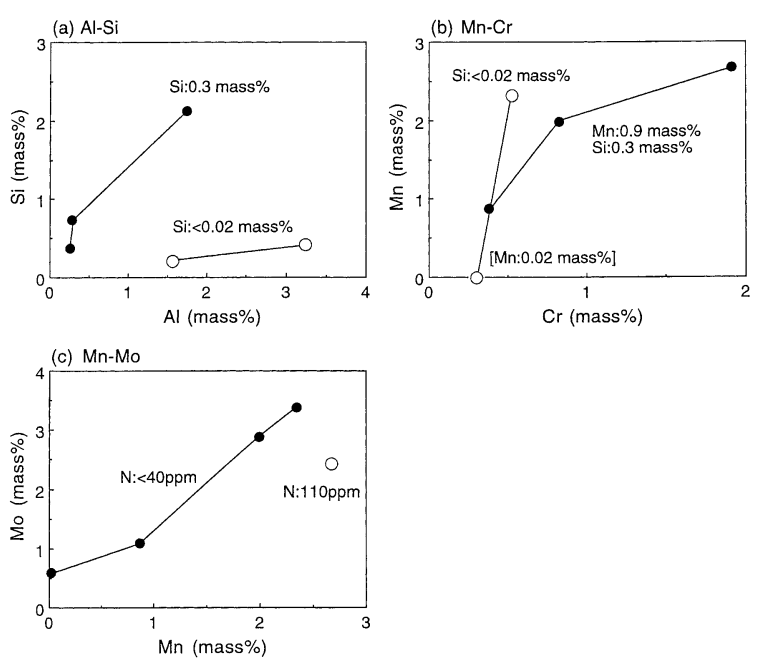

Fig. 9. The correlation of grain boundary segregation between selected two alloying elements in $5 \% \mathrm{Ni}$ steels as a directly proportional type.

are seen between $\mathrm{Al}$ and $\mathrm{Mn}$, between $\mathrm{Si}$ and $\mathrm{Cr}$ and between $\mathrm{Si}$ and $\mathrm{Mn}$ caused by the resultant solute interactions both in matrices and in grain boundaries. Hence, the attractive interaction between $\mathrm{Si}$ and $\mathrm{Mn}$ is definitely denied by the present result in Fig. 8, as predicted by the previous works. $^{10,16)}$

On the other hand, attractive interactions, which may cause cosegregation, are observed between $\mathrm{Al}$ and $\mathrm{Si}$, between $\mathrm{Cr}$ and $\mathrm{Mn}$ and between $\mathrm{Mn}$ and $\mathrm{Mo}$ in Fig. 9. However, the attractive interaction between $\mathrm{Al}$ and Si may be apparent as the resultant solute interactions both in matrices and in grain boundaries among different $5 \% \mathrm{Ni}$ steels, since the solute interaction between $\mathrm{Al}$ and $\mathrm{Si}$ was considered to be repulsive by the previous studies. ${ }^{10,22)}$

The present discussions eventually support the aforesaid hypothesis on the divorced coincident segregation. The segregating behavior of alloying elements is then governed by the three basic processes. First, all the solutes tend to segregate to grain boundaries according to the mechanism of McLean's equilibrium segregation. ${ }^{18)}$ Second, alloying elements with attractive interactions tend to cosegregate to one 
side of grain boundaries. Third, alloying elements with repulsive interactions each other tend to occupy the opposite side of grain boundaries due to the moderate site competitions, resulting in the divorced coincident segregation.

\subsubsection{Solute Interactions in Grain Boundaries of $5 \% \mathrm{Ni}$ Steels}

Figures 10 clarifies a solute interaction between $\mathrm{Al}$ and $\mathrm{Si}$, being rearranged from the segregated concentrations of $\mathrm{Al}$ and $\mathrm{Si}$ along grain boundaries shown in Fig. 5.

It is clearly noted in Fig. 10 that the segregated concentration of $\mathrm{Al}$ is inversely related to that of $\mathrm{Si}$ in Steel C, which obviously indicates the repulsive interaction between $\mathrm{Al}$ and $\mathrm{Si}$ in grain boundaries. This observation is quite different from the aforesaid result of the apparent attractive interaction between $\mathrm{Al}$ and Si shown in Fig. 9. Besides, the point deviated largely from the trend line of Steel $\mathrm{C}$ in Fig. 10 is correspondent to a point for the distance of $1 \mathrm{~nm}$ in Fig. 5, as discussed later in Fig. 14.

It is also noted in Fig. 10 that the matrix concentration of Al extremely enhances the grain boundary segregation of $\mathrm{Al}$ or Si in Steel C, as compared with that in Steel D. The matrix concentration of $\mathrm{Si}$ also increases the grain boundary segregation of $\mathrm{Si}$ or $\mathrm{Al}$ in Steel $\mathrm{C}$, as compared with that in Steels B.

It is then concluded in $5 \% \mathrm{Ni}$ steels that the repulsive interaction between $\mathrm{Al}$ and $\mathrm{Si}$ is an intrinsic phenomenon both in grain boundaries and in matrices.

\subsection{Influence of Solute Interactions on Grain Boun- dary Segregation in a Plain-carbon Steel}

Figures 11, 12 and 13 exhibit solute interactions between

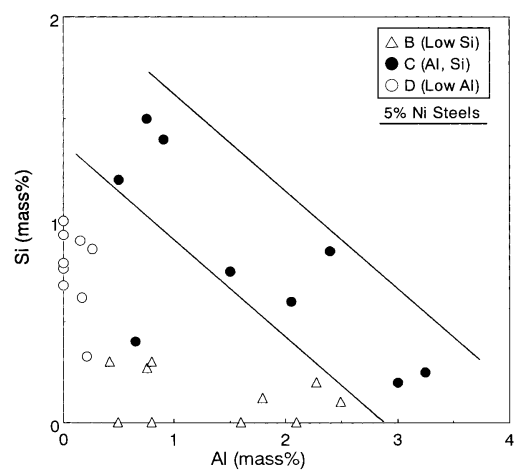

Fig. 10. Solute interaction between $\mathrm{Al}$ and $\mathrm{Si}$ in $5 \% \mathrm{Ni}$ Steels $\mathrm{B}$, $\mathrm{C}$ and D rearranged from Fig. 5.
$\mathrm{Al}$ and $\mathrm{Si}$, between $\mathrm{Al}$ and $\mathrm{P}$ and between $\mathrm{Si}$ and $\mathrm{P}$ in grain boundaries of Steel X, respectively. They were rearranged from the segregated concentrations of $\mathrm{Al}, \mathrm{Si}$ and $\mathrm{P}$ along grain boundaries of a plain-carbon steel shown in Fig. 7.

The repulsive interaction between $\mathrm{Al}$ and $\mathrm{Si}$ is distinctly demonstrated in Fig. 11 only except for a point corresponding to the distance of $9 \mathrm{~nm}$ shown in Fig. 7. The present observation definitely proves that the repulsive interaction between $\mathrm{Al}$ and $\mathrm{Si}$ is a common phenomenon not only in 5\% $\mathrm{Ni}$ steels but also in a plain-carbon steel, being associated with the periodic alternating segregation of $\mathrm{Al}$ and $\mathrm{Si}$ as shown in Figs. 5 and 7.

However, any relationship is not clearly seen between $\mathrm{Al}$ and $\mathrm{P}$ in Fig. 12. This result is not consistent with previous data showing the repulsive interaction between $\mathrm{Al}$ and $\mathrm{P}^{10,21)}$

On the other hand, the attractive interaction between $\mathrm{Si}$ and $\mathrm{P}$ obviously appears in Fig. 13, although the observation does not coincide with previous data on interaction coefficient. ${ }^{10,21,22)}$ Thus, this result indicates the apparent cosegregation of $\mathrm{Si}$ and $\mathrm{P}$ as predicted before in Fig. 7. It still remains unknown why the attractive interaction between $\mathrm{Si}$ and $\mathrm{P}$ apparently exists without being affected by other repulsive interaction between $\mathrm{P}$ and the third solute. $\mathrm{Al}$ is already denied as the candidate for the third solute by the result in Fig. 12. Then, the apparent cosegregation of $\mathrm{Si}$ and $\mathrm{P}$ may result from the repulsive interaction between $\mathrm{Si}$ and $\mathrm{C}$ followed by the strong site competition between $\mathrm{C}$ and $\mathrm{P}^{10,21)}$

In summary, it is concluded that the periodic alternating segregation of $\mathrm{Al}$ and $\mathrm{Si}$, which is derived from the repulsive interaction between $\mathrm{Al}$ and $\mathrm{Si}$, is not a peculiar phenomenon in $5 \% \mathrm{Ni}$ steels but a common one in any kind of steels.

\subsection{Comparison of Grain Boundary Segregation be- tween Simulation and Experiment}

Figure 14 compares the periodic segregation of $\mathrm{Si}$ between a simulated result and the experimental one for an $\mathrm{Fe}-\mathrm{Al}-\mathrm{Si}$ system on the basis of Steel C. The result demonstrates a good agreement except for the distance of $1 \mathrm{~nm}$. This discrepancy is also seen to correspond to the point deviating from the trend line in Fig. 10. Then, the measured value of $\mathrm{Si}$ at the distance of $1 \mathrm{~nm}$ seems to include some experimental errors or the strong affection of other solutes.

It is consequently concluded that the periodic alternating

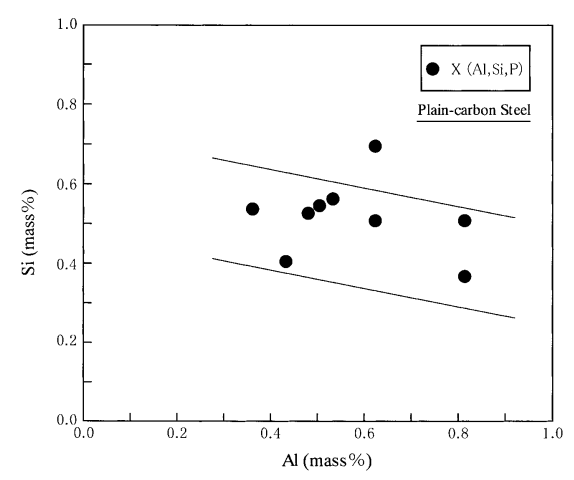

Fig. 11. Solute interaction between $\mathrm{Al}$ and $\mathrm{Si}$ in plain-carbon Steel $\mathrm{X}$ rearranged from Fig. 7.

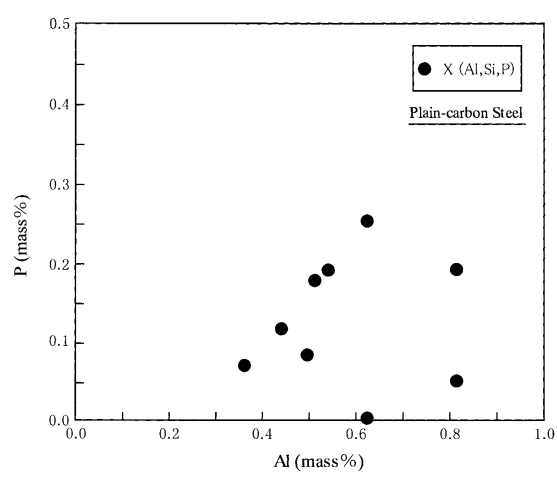

Fig. 12. Solute interaction between $\mathrm{Al}$ and $\mathrm{P}$ in plain-carbon Steel $\mathrm{X}$ rearranged from Fig. 7.

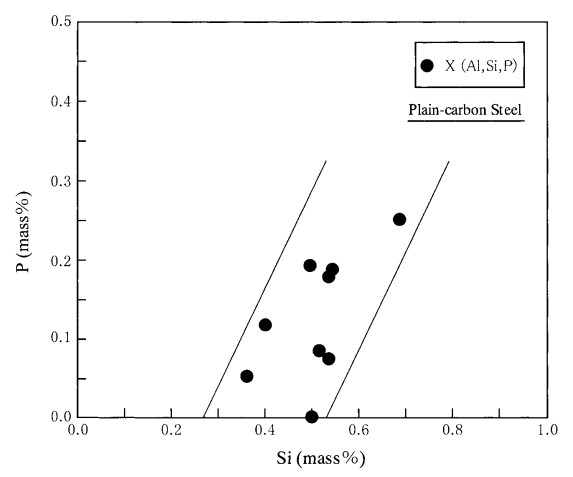

Fig. 13. Solute interaction between $\mathrm{Si}$ and $P$ in plain-carbon Steel $X$ rearranged from Fig. 7. 


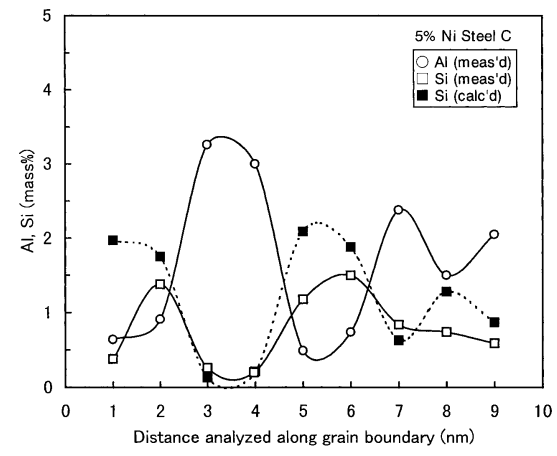

Fig. 14. Simulated periodic alternating segregation of $\mathrm{Si}$ for an $\mathrm{Fe}-\mathrm{Al}-\mathrm{Si}$ system in $5 \%$ Ni Steel C, compared with experimental one.

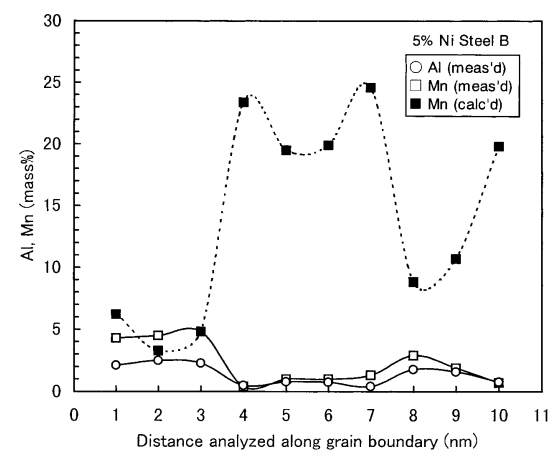

Fig. 15. Simulated periodic alternating segregation of $\mathrm{Mn}$ for an Fe-Al-Mn system in $5 \%$ Ni Steel B, compared with experimental one.

segregation of $\mathrm{Al}$ and $\mathrm{Si}$ is caused by the compositional fluctuation under the condition of positive interaction coefficient such as spinodal decomposition, although the concentration of segregated $\mathrm{Al}$ and $\mathrm{Si}$ of up to $3 \%$ is too low to compare with that of the conventional spinodal decomposition. However, the usage of Thermo Calc is extremely effective to simulate the periodic alternating segregation, even though the grain boundary structure was assumed to be liquid phase or amorphous phase.

An additional simulation was subsequently tried to seek the third solute, which could compensate the change in total Gibbs energy caused by the periodic segregation of $\mathrm{Al}$ for an Fe-Al-X system on the basis of Steel B. Only Mn of the chemical composition listed in Table 1 was assessed by using Thermo Calc in this case. Figure 15 describes the simulated periodic segregation of $\mathrm{Al}$ and $\mathrm{Mn}$. It is clearly demonstrated that the solute interaction between $\mathrm{Al}$ and $\mathrm{Mn}$ is not attractive but repulsive. Thus, the attractive interaction between $\mathrm{Al}$ and $\mathrm{Mn}$ for Steel B in Fig. 6 is concluded to be apparent due to the resultant solute interaction in multi-component steels.

Steel B in Fig. 6 shows that the concentration of Mn seems to be related periodically to that of $\mathrm{Al}$ in the grain boundary, implying that the presence of the third solute such as $\mathrm{Ni}, \mathrm{Cr}, \mathrm{P}$ or $\mathrm{S}$ is expected as a potential candidate so as to render the total Gibbs energy constant. ${ }^{1021-23)}$ Other EDS data for Steel B employed in Fig. 6 are accordingly reviewed to consider which alloying element could be the third solute to compensate the change in the total Gibbs energy.

Figure 16 shows the variations of $\mathrm{Ni}$ and Mo analyzed

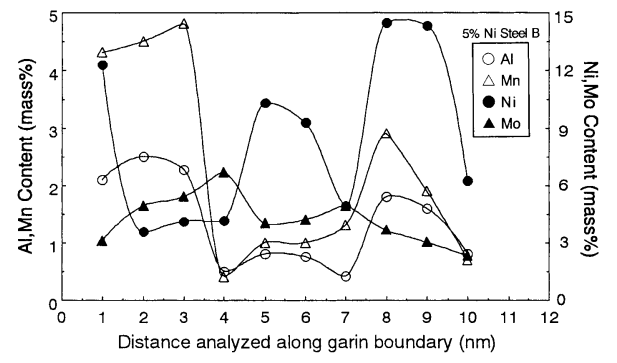

Fig. 16. The periodic segregation of $A l$ and $X$ as $X=N i$ and $M o$ as the third solute in $5 \%$ Ni Steel B, being superimposed on Fig. 6.

along grain boundaries as the third solute in Steel B, being superimposed on Fig. 6. The concentration of Ni varies alternately with that of $\mathrm{Al}$ except for the distance from $8 \mathrm{~nm}$ to $10 \mathrm{~nm}$. However, that of Mo does vary alternately with that of $\mathrm{Ni}$ in the whole range investigated.

It is then proved by Fig. 16 that $\mathrm{Ni}$ is the definite solute rather than a potential candidate as the third solute in Steel $\mathrm{B}$ to compensate the change in the total Gibbs energy. It still remains unclear why $\mathrm{Mn}$ apparently cosegregates with $\mathrm{Al}$ in Steel B.

On the other hand, it is first shown that the grain boundary periodic alternating segregation based on the divorced coincident segregation mechanism might be caused by the compositional fluctuation such as spinodal decomposition, although the concentration of $\mathrm{Al}$ and $\mathrm{Si}$ segregated to grain boundaries is too low to compare with that of the conventional spinodal decomposition.

\subsection{Dimensional Extension of Grain Boundary Peri- odic Alternating Segregation}

It is important to reconfirm that the periodic alternating segregation of $\mathrm{Al}$ and $\mathrm{Si}$ appears along grain boundaries on the basis of the divorced coincident segregation due to their strong repulsive interaction, as shown in Fig. 5.

By adopting the concept of the point symmetry, one-dimensional periodic alternating segregation is able to be extended inductively to two-dimensional contour map of segregated solutes A and B on the surface of grain boundaries, as schematically illustrated in Fig. 17. High concentration regions of segregated solute A and low concentration regions of segregated solute B are depicted by solid circles, and vice versa by dotted circles.

It is consequently inferred in Fig. 17 that the ideal periodic alternating segregation can depend on the directions of analyzing sections, as three different profiles of segregated solutes A and B along grain boundaries are deductively demonstrated. The perfect periodic alternating segregation of $\mathrm{A}$ and $\mathrm{B}$ can be obtained along the direction analyzed on the a-a section, as just shown by Steel C in Fig. 5. On the other hand, the partial periodic alternating segregation of $\mathrm{A}$ and $\mathrm{B}$ can appear along the direction analyzed on the $\mathrm{c}-\mathrm{c}$ section, as also shown by Steel X in Fig. 7. Hence, the twodimensional extension of the periodic alternating segregation is rationalized by the present consideration.

Three-dimensional contour map of segregated solutes A and $\mathrm{B}$ is inductively obtained simply by combining the divorced coincident segregation in Fig. 4(a) and two-dimensional contour map of segregated solutes on the surface of grain boundaries in Fig. 17, as illustrated in Fig. 18(A). 

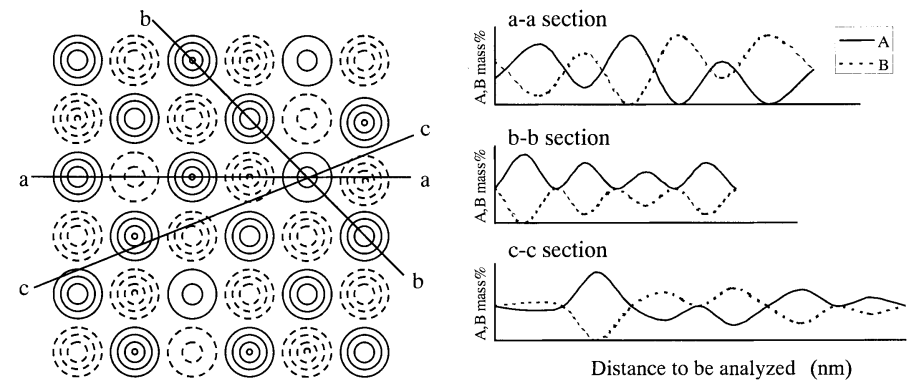

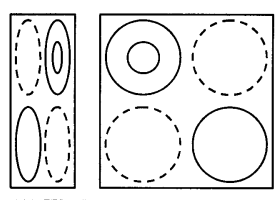

(A) Weak repulsive interaction
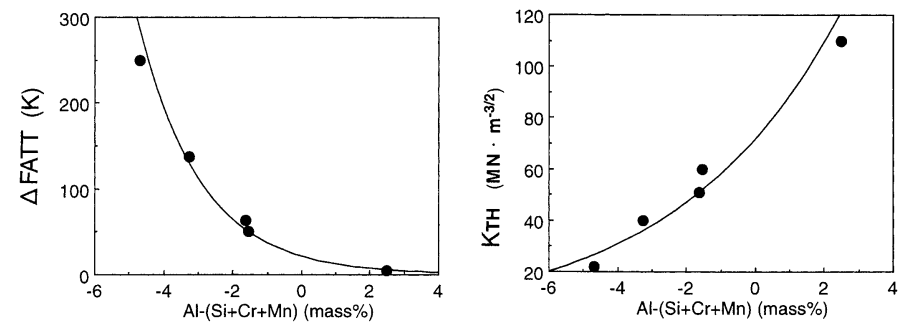

Fig. 17. Two-dimensional extension of the periodic alternating segregation, showing the contour map of segregated solutes A and $\mathrm{B}$ and their typical variation.

Fig. 18. Three-dimensional extension of the periodic alternating segregation to the contour map of segregated solutes A and B.

Fig. 19. The influence of segregated $\mathrm{Al}, \mathrm{Si}, \mathrm{Cr}$ and $\mathrm{Mn}$ on temper embrittlement and hydrogen embrittlement in $5 \% \mathrm{Ni}$ steels.
However, it is observed that the divorced coincident segregation is comparatively indistinct as shown in Figs. 2 and 3, while the periodic alternating segregation is much more distinct as shown in Figs. 5 to 7. Then, Fig. 18(A) may lead to the inverse understanding against the aforesaid observation.

Thus, the three-dimensional model has to be modified as a function of the repulsive intensity by considering the influence of site competition. Figures 18(A), 18(B) and 18(C) indicate the cases of the weak repulsive interaction, moderate one and strong one, respectively. In short, Fig. 18(A) is correspondent to the periodic alternating segregation of $\mathrm{Si}$ and $\mathrm{Mn}$ with the long wavelength. Figure $18(\mathrm{~B})$ is also correspondent to that of $\mathrm{Al}$ and $\mathrm{Si}$ with short one. Besides, Fig. 18(C), which is combined by Fig. 4(b), is correspondent to the strong site competition without the divorced coincident segregation. However, it is not the conventional site competition but newly predicted genuine one. Figure $18(\mathrm{C})$ depicts obviously that segregated solutes vary alternately along grain boundaries in the case of the newly predicted site competition.

In short, Figs. 18(A), 18(B) and 18(C) are correspondent to the indistinct divorced coincident segregation, distinct one and the genuine site competition, respectively. Then, it is concluded that all the conventional site competition should be replaced by the divorced coincident segregation and the genuine site competition, where segregated solutes vary alternately along grain boundaries.

The three-dimensional model of the periodic alternating segregation seems to be complicated, but it is rather simple if one can understand the formation mechanism of the periodic alternating segregation associated with the divorced coincident segregation mechanism. The present consideration shown in Figs. 17 and 18 could not have been achieved until the discovery of the periodic alternating segregation based on the divorced coincident segregation mechanism by conducting FE-TEM-EDS analyses. It is then necessary to consider that previous research activities including grain boundary segregation are to be restudied from different viewpoints whenever one obtains a new means to analyze materials such as FE-TEM with $1 \mathrm{~nm}$-probe.

\subsection{Effect of Soluble Al on the Suppression of Two Types of Embrittlement}

It is shown in Fig. 19 that soluble Al suppresses extremely temper embrittlement and hydrogen embrittlement caused by the grain boundary segregation of $\mathrm{Si}, \mathrm{Cr}$ and $\mathrm{Mn}$. Figure 19 was rearranged from $\Delta$ FATT and $K_{\mathrm{Th}}$ shown in Table 2 and from the averaged intergranular concentrations of alloying elements shown in Fig. 1. The result shows that the amount of $\{\mathrm{Al}-(\mathrm{Si}+\mathrm{Cr}+\mathrm{Mn})\}$ in grain boundaries governs the resistance to the two types of embrittlement in $5 \% \mathrm{Ni}$ steels.

The influence of $\mathrm{Si}$ on the two types of embrittlement was empirically understood by the averaged value of segregated $\mathrm{Si}$ in grain boundaries until now. However, the beneficial effect of soluble $\mathrm{Al}$ in the improved $5 \% \mathrm{Ni}$ steels with high $\mathrm{Al}$ is accordingly attributed to the suppression of $\mathrm{Si}$ segregation owing to the repulsive interaction between $\mathrm{Al}$ and $\mathrm{Si}$ as shown in Fig. 10, and also to the mechanism of spot toughening like spot welding through the periodic decrease of segregated $\mathrm{Si}$ as shown in Fig. 5.

\subsection{Other Issues}

The present results may be argued from the following viewpoints. ${ }^{24)}$ One is the influence of the grain boundary structure on grain boundary segregation as a function of the misorientation angle between two adjacent prior austenitic grains. The other is the stability of EDS analyses on the influence of sample thickness and grain boundary slope associated with the on edge observation of EDS analyses. 
In the former case, the grain boundary concentration of solutes are essentially governed by their segregation enthalpies, which depend on the boundary orientation as a function of the deviation angle of boundary planes. ${ }^{25,26)}$ The influence of the change in the segregation enthalpies on grain boundary segregation is considered to be common for each solute and irrelevant to interactions between solutes, then the present result on the grain boundary periodic alternating segregation based on the divorced coincident segregation is not influenced so much by prior austenitic grain boundary structure.

In the latter case, the accuracy of EDS analyses is extremely important in elucidating the mechanism of solute segregation. The present study has been carefully carried out by using the thin foil specimen with a thickness of $5 \mathrm{~nm}$ or less for EDS analyses of $1 \mathrm{~nm}$-probe, avoiding the neighborhood of existing precipitates. Even though EDS analyses are qualitatively influenced by sample thickness and the on edge observation, the grain boundary periodic alternating segregation based on the divorced coincident segregation has been elucidated for various steels in the present study. The above results are definitely considered to be on the safe side, since both the asymmetric segregation and the alternating segregation may have a large possibility to disappear when the inaccuracy of EDS analyses is increased due to the influence of sample thickness and the on edge observation.

\section{Conclusions}

The divorced coincident segregation with asymmetric profiles was investigated by employing FE-TEM-EDS with respect to the influence of solute interactions on the segregating behavior of alloying elements in the improved $5 \%$ $\mathrm{Ni}$ steels with no or almost no intergranular fracture. The periodic alternating segregation of $\mathrm{Al}$ and $\mathrm{Si}$ was first found by the present study both in $5 \% \mathrm{Ni}$ steels and in a plaincarbon steel. Hence, the result supports that the principle of the divorced coincident segregation proposed in $5 \% \mathrm{Ni}$ steels can be applicable not only to any kinds of steels but also to other poly-crystalline alloys in improving their properties.

It is consequently elucidated by the assistance of Thermo Calc that the periodic alternating segregation is brought about by compensating the change in the total Gibbs energy under the condition of positive interaction coefficient. The compositional fluctuation is considered to be the formation mechanism of the periodic alternating segregation just like spinodal decomposition, although the concentration of solutes segregated to grain boundaries is too low to compare with that of the conventional spinodal decomposition.

Three-dimensional contour map of segregated solutes A and $\mathrm{B}$ is proposed from the point symmetric concept of the periodic alternating segregation based on the divorced coincident segregation mechanism, demonstrating that the concentration profiles of segregated solutes along grain boundaries depend on the direction of analyses.

It is also concluded that all the conventional site competition may be replaced by the newly proposed divorced coincident segregation and the genuine site competition, where segregated solutes vary alternately along grain boundaries. In addition, the beneficial effect of soluble Al on temper embrittlement and hydrogen embrittlement is considered to be due to the suppression of segregated $\mathrm{Si}$ owing to the repulsive interaction between $\mathrm{Al}$ and $\mathrm{Si}$ and due to the mechanism of spot toughening through the periodic decrease of segregated $\mathrm{Si}$ in the improved $5 \% \mathrm{Ni}$ steels with high $\mathrm{Al}$.

It is finally recommended through the present investigation that previous research activities have to be restudied with the advent of the new means applicable to analyze materials from different viewpoints.

\section{Acknowledgements}

The authors acknowledge Professor Charles J. McMahon, Jr., University of Pennsylvania for his helpful advice in defining the divorced coincident segregation in the present study. They dedicate their paper to late Professor Hideo Abe, University of Tokyo for his giving them the original incentive in elucidating the segregation mechanism of solutes in improved $5 \% \mathrm{Ni}$ steels. The operation of FETEM analyses by Dr. Ryuji Uemori, Steel Research Laboratories, Nippon Steel Corporation is also acknowledged in the present paper. They also acknowledge Mr. Masanori Minagawa, Oita R\&D Laboratories, Nippon Steel Corporation for his assistance on the dimensional extension of the grain boundary periodic alternating segregation.

\section{REFERENCES}

1) R. Bruscato: Welding, Res. Suppl., 49 (1970), 148s

2) T. Wada: Climax Molybdenum Co. of Michigan, Feb. (1975), RP-3274-03.

3) C. L. Briant and S. K. Banerji: Metall. Trans. A, 10A (1979), 1729.

4) Jun Kameda and C. J. McMahon, Jr.: Metall. Trans. A, 12A (1981), 31 .

5) L. F. Porter, G. C. Carter and S. J. Manganello: Temper Embrittlement in Steel, ASTM STP, 407 (1968), 20.

6) U. Q. Cabral, A. Hache and A. Constant: C. R. Acad. Sci. (Paris), 260 (1965), 6887.

7) K. Yoshino and C. J. McMahon, Jr.: Metall. Trans., 5 (1974), 363.

8) C. L. Briant, H. C. Feng and C. J. McMahon, Jr.: Metall. Trans., 9A (1978), 625

9) H. Mabuchi and C. J. McMahon, Jr.: Proc. JIMIS-2, Hydrogen in Metals, Suppl. Trans. Jpn. Inst. Met., 21 (1980), 441.

10) H. Mabuchi: Trans. Iron Steel Inst. Jpn., 22 (1982), 967.

11) Y. Takeda and C. J. McMahon, Jr.: Metall. Trans., 13A (1982), 111.

12) H. L. Marcus, L. H. Hackett, Jr. and P. W. Palmberg: ASTM STP, 499 (1972), 90.

13) H. Mabuchi and R. Uemori: Proc. on 38th Mechanical Working and Steel Processing Conf., ISS, Warrendale, PA, Vol. 34 (1997), 611.

14) H. Mabuchi: CAMP-ISIJ, 10 (1997), 589.

15) H. Mabuchi and R. Uemori: ISIJ Int., 38 (1998), 203.

16) H. Mabuchi, R. Uemori and T. Koseki: ISIJ Int., 39 (1999), 937.

17) B. Sundman, B. Jansson and J. O. Andersson: Calphad, 9 (1985), 153.

18) D. McLean: Grain Boundaries in Metals, Oxford Univ. Press, Oxford, (1957), 116.

19) P. Haasen: Physical Metallurgy, Cambridge University Press, Cambridge, (1986), 216.

20) J. W. Christian: The Theory of Transformation in Metals and Alloys, Pergamon Press, Oxford, (1975), 394.

21) H. Kaneko, T. Nishizawa and K. Tamaki: J. Jpn. Inst. Met., 29 (1965), 159.

22) J. F. Elliot, M. Gleiser and V. Ramakrishna: Thermochemistry for Steelmaking, Adison-Wesley Publishing Co., Reading, Mass., Vol. 2 (1963), 564.

23) H. Kaneko, T. Nishizawa and K. Tamaki: J. Jpn. Inst. Met., 27 (1963), 299

24) D. E. Laughlin: Private Communication, Carnegie Mellon University.

25) P. Lejcek, J. Adamek and S. Hofmann: Surf. Sci., 264 (1992), 449.

26) G.Herrmann, H. Gleiter and G. Baro: Acta Metall., 24 (1976), 353. 